\title{
The dynamics of mortality in follow-up time after an acute myocardial infarction, lower extremity arterial disease and ischemic stroke
}

\author{
Ilonca Vaartjes ${ }^{1 *}$, Ineke van Dis ${ }^{2}$, Diederick E Grobbee ${ }^{1}$, Michiel L Bots ${ }^{2}$
}

\begin{abstract}
Background: Most studies providing data on survival in patients with atherosclerosis only address a single disease site: heart, brain or legs. Therefore, our objective was to determine risk of death after first hospital admission for atherosclerotic disease located at different sites.

Methods: A nationwide cohort of patients hospitalized for the first time for acute myocardial infarction (AMI), peripheral arterial disease of the lower extremities (PAD) or ischemic stroke was identified through linkage of national registers. The mortality rate in AMI patients was compared to mortality rate in ischemic stroke and PAD patients by estimating relative risks (with 95\%Cl). Cox's proportional hazard models were used to estimate sex differences in risk of death.

Results: Case fatality was high for ischemic stroke patients (men:21.0\%, women:23.8\%) and AMI patients (men:12.7\%, women:20.9\%) though low for PAD patients (men:2.4\%, women:3.5\%). The five-year risk of death was similar for male AMI compared to PAD patients (men: RR1.04; 95\% $0.98-1.11$ ). The risk of death for ischemic stroke patients remained the highest though the differences with AMI and PAD patients attenuated.

Conclusions: The dynamics of mortality over follow-up time clearly differ between atherosclerotic diseases, located at different vascular beds. The risk of death increases considerably over follow-up time for PAD patients, and 5 years after first hospital admission the differences in risks of death between AMI- and PAD patients and between AMl- and ischemic stroke patients have largely attenuated. Clinicians should be aware of these dynamics of mortality over follow-up time to provide optimal secondary prevention treatment.
\end{abstract}

\section{Background}

Atherosclerosis is a systemic disease leading to various symptoms and clinical events. Acute myocardial infarction (AMI), ischemic stroke and peripheral arterial disease of the lower extremities (PAD) are common atherosclerotic manifestations, by which the coronary arteries, carotid arteries and peripheral arteries of the lower extremities respectively, play a major role. In recent decades, clinical and population-based studies have provided extensive data on the prognosis of patients diagnosed with atherosclerosis [1]. These data primarily address the prognosis of one manifestation of atherosclerotic disease rather than different manifestations of

\footnotetext{
* Correspondence: c.h.vaartjes@umcutrecht.nl

'Julius Center for Health Sciences and Primary Care, University Medical

Center Utrecht, Utrecht, the Netherlands

Full list of author information is available at the end of the article
}

atherosclerosis [2,3]. Several studies have reported associations of cardiovascular risk factors with progression of atherosclerosis $[4,5]$, although the association of the risk factors with progression of atherosclerosis is inconsistent across different vascular beds [6]. This might suggest that prognosis of patients diagnosed with atherosclerosis may depend on the location of the vascular bed where atherosclerosis predominantly becomes manifest.

In a previous study, where we used parts of the data from the present study, we investigated long-term prognosis of PAD and compared mortality among first hospitalized PAD patients with mortality among patients first hospitalized for stroke and AMI. We reported that five-year death rate was somewhat higher among stroke patients and almost similar for PAD and AMI patients [7]. Caro et al. [8] investigated potential risk factors for PAD mortality and presented long term survival among 
PAD patients together with survival among patients suffering from stroke and AMI. They reported that the crude five-year death rate among patients diagnosed with PAD was lower than death rates among patients diagnosed with stroke, but higher than death rates among patients diagnosed with AMI. These studies suggest that there may be a different prognosis per manifestations of atherosclerosis. However, these studies did not include short-term prognosis [7] or did not provide ageand sex-specific mortality [8], despite the evidence that mortality depends on age and gender. The purpose of the present study, therefore, was to estimate both detailed short-term and long-term mortality risks, stratified by age and gender, in a large, nationwide cohort of patients first hospitalized for AMI, ischemic stroke and PAD.

\section{Methods}

For the present study, cohorts were drawn from 1995, 1997 and 2000. The choice of years was pragmatic at the time the project was initiated in 2001. The total population of the Netherlands in 1995, 1997 and 2000 was $15,424,122$ (men $7,627,428$, women $7,796,640$ ), $15,567,107$ (men 7,696,803, women 7,870,304) and 15,863,950 (men: 7,846,317, women: 8,017, 633), respectively. Approximately $14 \%$ of the population was older than 65 years. To construct a cohort of patients admitted for the first time due to ischemic stroke, AMI and PAD, information from the national Hospital Discharge Register (HDR) and the Population Register (PR) were linked. Information on cause of death has been derived from the Cause of Death Register of Statistics Netherlands. The registers and linkage procedures have been described in detail previously for a cohort of acute myocardial infarction [9] and stroke patients [10].

\section{Cohort enrolment}

All hospital admissions for acute myocardial infarction (AMI) between January $1^{\text {st }}$ and December $31^{\text {st }} 1995$, (ICD-9-CM code 410, ICD-10-CM code I21) and all hospital admissions for ischemic stroke (ICD-9-CM code 434, 436, ICD-10-CM code I63) and peripheral arterial disease of the lower extremities (PAD) (ICD-9CM code 443.9, ICD-10-CM code I73.9) between January $1^{\text {st }}$ and December $31^{\text {st }} 1997$ and January $1^{\text {st }}$ and December $31^{\text {st }} 2000$ respectively, were selected. No information on severity of disease was available. Therefore, we assumed that PAD patients diagnosed with ICD-9 code 443.9 (peripheral vascular disease unspecified, intermittent claudication not otherwise specified (NOS). Peripheral: angiopathy NOS, vascular disease NOS, Spasm of artery. Excluded are atherosclerosis of the arteries of the extremities and spasm of cerebral artery) represents patients hospitalized with moderate/ severe claudication, ischemic rest pain and ulceration or gangrene (Fontaine stage IIb, III and IV respectively), as these patients have an indication for surgical interventions [11].

By merging with the PR, only those patients with a unique combination (linkage variables date of birth, sex and numerical part of postal code) were selected. Next, the first hospital admissions in 1995 for AMI and in 1997 and 2000 for ischemic stroke and PAD were selected. To identify first admissions, the file was merged with a file in which, through the same linkage procedures, information was collected on hospital admissions that occurred previously (1991-1995, 19951997 and 1995-2000 respectively) for the same condition. For the years 1991-1994 a different - and slightly less reliable - linkage procedure was used, because the digital PR only started in 1995 [12]. Those with a previous admission for the same condition were excluded, for example, those with a previous hospitalization for cerebrovascular accident (CVA) were excluded from the ischemic stroke cohort, but not from the cohorts dealing with PAD or AMI. This approach left a cohort of patients admitted to hospital for the first time because of the occurrence of ischemic stroke, PAD or AMI. Finally, the cohort was linked with the Cause of Death Register to obtain information on date and cause of death (in-hospital and out-of-hospital) during follow-up. Patients were censored if they migrated out of the Netherlands during follow-up.

\section{Comorbidity}

The presence of comorbidity (cardiovascular diseases (ICD-9-CM codes 390-459) or diabetes mellitus (ICD-9CM code 250)) was determined on the basis of the discharge diagnosis of previous hospital admissions or on the basis of a secondary diagnosis at the moment of the index admission.

No information on risk factors (hypertension, smoking) or medication use was available in the register.

\section{Data analysis}

Analyses were performed for AMI, ischemic stroke and PAD. Survival time was calculated as the time from the initial admission date in 1995 for AMI and 1997 or 2000 for ischemic stroke and PAD, to the date of death from any cause, or to the date that a patient was censored, whichever came first. The 28-day case-fatality, 1-year and long-term (5-year) mortality was computed by age and gender according to the actuarial life table method and expressed as percentages. To make results comparable with other community-based studies, the overall rates were adjusted to the European standard population [13]. The 1-year and long-term (5-year) mortality was also computed for patients who survive for at 
least 28 days after hospital admission. Cox regression models were used to study gender differences in mortality at 28 days, 1 year and 5 years. For each period, a model was used to adjust for age. Results were presented as hazard ratios (with $95 \% \mathrm{CI}$ ). The mortality rate in AMI patients was compared to the mortality rate in ischemic stroke patients and PAD patients by calculating relative risks (with 95\%CI). Data were analyzed with SPSS software, version 14.0 (SPSS Inc, Chicago, Illinois, USA).

Approval for the use of the anonymized patient data was covered by a general agreement between Statistics Netherlands and Dutch Hospital Data (DHD). Additionally, the Dutch association of hospitals (NVZ) and Dutch federation of University Hospitals (NFU) approved the use of the hospital registration data for this study. No separate ethical approval was necessary for the use of these data. All analyses were performed in accordance with privacy legislation in the Netherlands [14].

\section{Results}

More men than women were hospitalized for first AMI $(14,463$ men, 7,102 women) in 1995 and PAD $(2,539$ men, 1,619 women) in 1997 and 2000, while more women than men were hospitalized for first ischemic stroke (11,381 men, 12,150 women) in 1997 and 2000. General characteristics are provided in Table 1. In all three groups women were older than men. Men had more previous admissions for ischemic heart disease than women. Women were known to have diabetes mellitus more often than man. More men were admitted to academic hospitals than women. This difference was the most pronounced among PAD patients (men: 11.2\%, women: $7.8 \%$ ). The length of stay was longer for women than men. De mean length of stay was clearly the longest among ischemic stroke patients. The largest part of the patients (93\% of PAD patients, $94 \%$ of ischemic stroke patients and $95 \%$ of AMI patients) were diagnosed with an atherosclerotic manifestation at one location of the vascular bed (Figure 1). These patients had not been previously admitted for AMI, PAD and ischemic stroke.

\section{8-day case fatality}

In men, the 28-day case fatality after AMI, PAD and ischemic stroke was $12.7 \%, 2.4 \%$ and $21.0 \%$, respectively. In women this was $20.9 \%, 3.5 \%$ and $23.8 \%$ (Table 2). There were large variations in 28-day case fatality in the different age groups (Table 2). The risk of death in AMI patients was much higher compared to PAD patients (men: RR 5.57; 95\%CI 4.23 to 7.32, women: RR 6.64; 95\% CI 4.99 to 8.84 ) and lower compared to ischemic stroke patients (Table 3). In PAD, AMI and ischemic stroke patients the overall risk of death was higher for women. However, in the AMI group there were no longer differences in risk of death between men and women after adjustment for age (Table 4).

Table 1 Characteristics of patients with a first hospitalization in the Netherlands for acute myocardial infarction (AMI), peripheral arterial disease of the lower extremities (PAD) and ischemic stroke

\begin{tabular}{|c|c|c|c|c|c|c|}
\hline & \multicolumn{2}{|c|}{ AMI\# } & \multicolumn{2}{|c|}{ PAD +} & \multicolumn{2}{|c|}{ Ischemic strokeł } \\
\hline & Men & Women & Men & Women & Men & Women \\
\hline Number of patients & 14,463 & 7,102 & 2,539 & 1,619 & 11.381 & 12.150 \\
\hline \multicolumn{7}{|l|}{ Age at admission (years) } \\
\hline Mean & 64.3 & 71.9 & 66.1 & 66.9 & 70.2 & 74.7 \\
\hline Standard deviation & 12.3 & 11.8 & 11.6 & 13.9 & 12.3 & 13.1 \\
\hline $\begin{array}{l}\text { Previous hospitalization for: } \\
\text { cardiovascular disease }\end{array}$ & 17.8 & 18.5 & 28.9 & 25.0 & 21.4 & 20.0 \\
\hline - ischemic heart disease & 8.1 & 7.3 & 13.6 & 8.6 & 8.0 & 5.1 \\
\hline - acute myocardial infarction & 0.0 & 0.0 & 3.7 & 3.2 & 3.2 & 1.8 \\
\hline - stroke & 1.5 & 1.4 & 4.6 & 3.3 & 0.0 & 0.0 \\
\hline - peripheral arterial disease & 3.1 & 2.6 & 0.0 & 0.0 & 4.1 & 2.5 \\
\hline - heart failure & 2.1 & 3.1 & 3.9 & 3.5 & 2.9 & 3.6 \\
\hline - other cardiovascular disease & 6.3 & 7.5 & 14.0 & 15.2 & 11.6 & 13.4 \\
\hline diabetes mellitus & 6.7 & 7.2 & 10.8 & 13.3 & 11.1 & 13.7 \\
\hline $\begin{array}{l}\text { Type of hospital (\%) } \\
\text { - academic }\end{array}$ & 6.2 & 5.7 & 11.2 & 7.8 & 11.0 & 9.2 \\
\hline Length of stay (days) & 10 & 11 & 4 & 5 & 22 & 27 \\
\hline $\begin{array}{l}\text { Origin (\%) } \\
\text {-native Dutch }\end{array}$ & 89.3 & 90.0 & 91.5 & 89.5 & 89.9 & 88.9 \\
\hline
\end{tabular}

\# Cohort is based on patients first hospitalized for AMI in 1995, + Cohort is based on patients first hospitalized for PAD in 1997 or 2000

₹ Cohort is based on patients first hospitalized for ischemic stroke in 1997 or 2000 


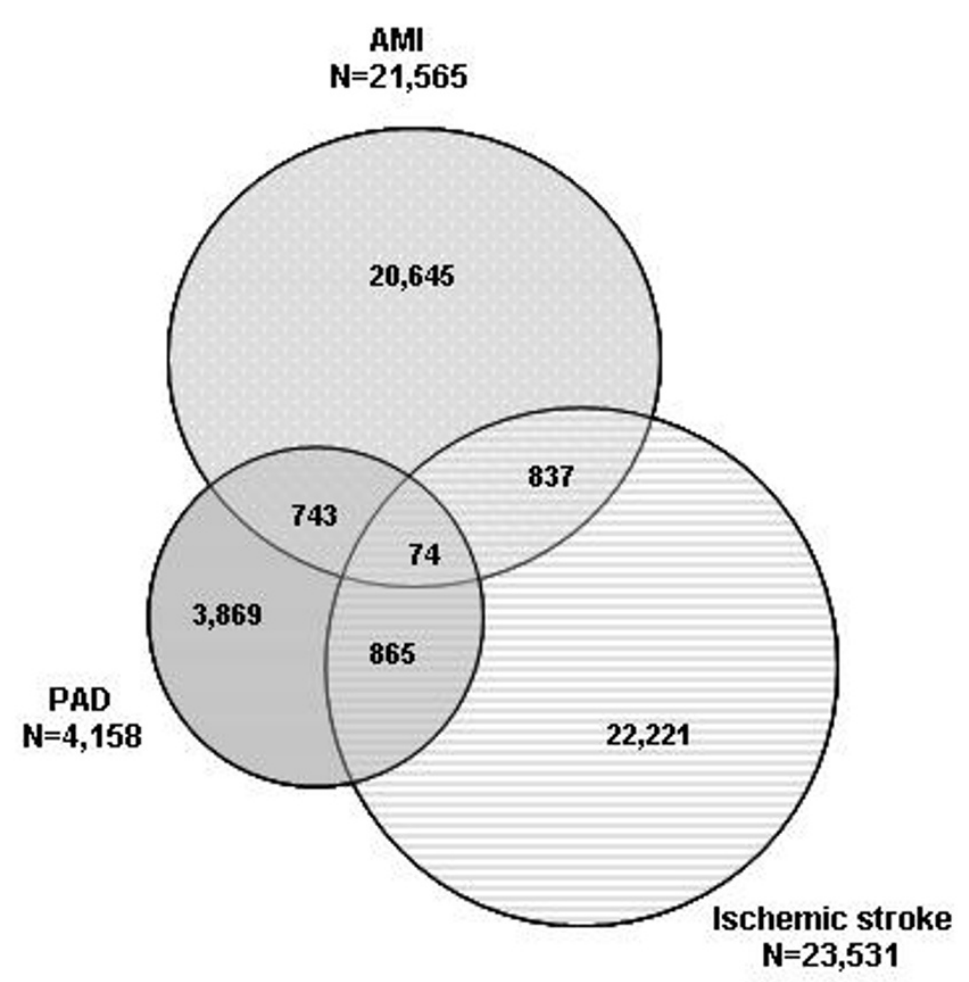

Figure 1 Diagram of patients first hospitalized for acute myocardial infarction (AMI), ischemic stroke, or peripheral arterial disease of the lower extremities (PAD). Number of patients diagnosed with atherosclerosis at single or multiple sites of vascular bed.

\section{One-year mortality}

Compared to 28-day case fatality, the differences in risk of death between AMI and PAD patients reduced in all age-sex-groups (Table 3). In PAD, AMI and ischemic stroke patients the overall risk of death was higher for women. However, after adjustment for age there were no differences in risk of death between men and women (Table 4).

In men, the 1-year risk of death among patients who survive for at least 28 days after first admission for AMI, PAD and ischemic stroke was $6.2 \%, 9.0 \%$ and $10.9 \%$, respectively. In women this was $9.2 \%, 7.1 \%$ and $13.0 \%$ (Table 5).

\section{Five-year mortality}

In men, the 5-year risk of death after AMI, PAD and ischemic stroke was $32.2 \%, 31.0 \%$ and $48.6 \%$, respectively. In women this was $44.5 \%, 27.4 \%$ and $53.0 \%$ (Table 2). Although 5-year risk of death was the highest for ischemic stroke patients, the difference between 1 -year and 5-year mortality risks among PAD patients sharply rises and clearly is the highest, especially among male PAD patients (Figure 2). In AMI and ischemic stroke patients the overall risk of death was higher for women. After adjustment for age the risk of death was higher in men than in women (age-adjusted hazard ratio for ischemic stroke, AMI, and PAD: 1.18 ; 95\%CI 1.14 to $1.23,1.06$; $95 \%$ CI 1.02 to $1.12,1.35 ; 95 \%$ CI 1.19 to 1.51 respectively) (Table 4 ).

In men, the 5-year risk of death among patients who survive for at least 28 days after first admission for AMI, PAD and ischemic stroke was $22.3 \%, 22.9 \%$ and $19.5 \%$, respectively. In women this was $29.7 \%, 24.7 \%$ and $39.6 \%$ (Table 5).

\section{Risk of death for patients without previous admissions for CVD}

Differences between PAD, AMI and ischemic stroke patients in the presence of comorbidity may affect relative risk of death. However, we repeated the analysis, and computed 28-day case fatality, 1-year and long-term (5-year) mortality by age and gender according to the actuarial life table method, excluding those patients with previous admissions for cardiovascular disease (CVD). Approximately $18 \%$ of AMI patients, $21 \%$ of ischemic stroke patients and $28 \%$ of PAD patients were excluded. The relative risks of death between the groups remained similar, except for 28-day case fatality, were relative risk for AMI compared to PAD patients increased (data not shown). 
Table 2 Mortality risk at 28 days, 1 year and 5 years after a first hospital admission for acute myocardial infarction (AMI), peripheral arterial disease in the lower extremities (PAD) and ischemic stroke, by age and gender

\begin{tabular}{|c|c|c|c|c|c|c|c|c|c|c|c|c|c|}
\hline & \multirow{3}{*}{ Age } & \multicolumn{4}{|c|}{ Acute myocardial infarction } & \multicolumn{4}{|c|}{ PAD } & \multicolumn{4}{|c|}{ Ischemic stroke } \\
\hline & & $\begin{array}{r}\text { No. of } \\
\text { men }\end{array}$ & $\begin{array}{r}\text { No. of } \\
\text { women }\end{array}$ & Men & Women & $\begin{array}{r}\text { No. of } \\
\text { men }\end{array}$ & $\begin{array}{r}\text { No. of } \\
\text { women }\end{array}$ & Men & Women & $\begin{array}{r}\text { No. of } \\
\text { men }\end{array}$ & $\begin{array}{r}\text { No. of } \\
\text { women }\end{array}$ & Men & Women \\
\hline & & & & $\begin{array}{r}\% \\
\text { deaths }\end{array}$ & $\begin{array}{r}\% \\
\text { deaths }\end{array}$ & & & $\begin{array}{r}\% \\
\text { deaths }\end{array}$ & $\begin{array}{r}\% \\
\text { deaths }\end{array}$ & & & $\begin{array}{r}\% \\
\text { deaths }\end{array}$ & $\begin{array}{r}\% \\
\text { deaths }\end{array}$ \\
\hline \multirow{6}{*}{$\begin{array}{r}\text { 28-day case } \\
\text { fatality }\end{array}$} & $<55$ & 3,424 & 656 & 4.1 & 5.8 & 478 & 339 & - & - & 1,336 & 1,145 & 6.8 & 7.5 \\
\hline & $55-74$ & 8,027 & 3,285 & 10.6 & 12.8 & 1,454 & 778 & 1.8 & 1.4 & 5,549 & 3,185 & 14.3 & 17.2 \\
\hline & $75-84$ & 2,563 & 2,346 & 26.3 & 29.8 & 531 & 385 & 5.3 & 5.7 & 3501 & 4739 & 29.2 & 25.6 \\
\hline & $85+$ & 449 & 815 & 38.8 & 40.0 & 76 & 117 & 18.4 & 18.8 & 995 & 2481 & 47.8 & 42.3 \\
\hline & Total & 14,463 & 7,102 & 12.7 & 20.9 & 2,539 & 1,619 & 2.4 & 3.5 & 11,381 & 12,150 & 21.0 & 23.8 \\
\hline & $\mathrm{ASR}^{*}$ & & & 6.0 & 8.2 & & & 0.5 & 0.5 & & & 7.6 & 9.0 \\
\hline \multirow{6}{*}{$\begin{array}{r}\text { 1-year } \\
\text { mortality }\end{array}$} & $<55$ & 3,424 & 656 & 5.5 & 7.3 & 478 & 339 & 2.5 & 1.5 & 1,336 & 1,145 & 8.9 & 8.9 \\
\hline & $55-74$ & 8,027 & 3,285 & 15.3 & 17.9 & 1,454 & 778 & $\begin{array}{r}7.9 \\
18.6\end{array}$ & 6.3 & 5,549 & 3,185 & 20.9 & 20.1 \\
\hline & $75-84$ & 2,563 & 2,346 & 37.4 & 39.1 & 531 & 385 & 47.4 & 16.6 & 3501 & 4739 & 42.2 & 36.4 \\
\hline & $85+$ & 449 & 815 & 56.3 & 55.6 & 76 & 117 & 10.3 & 41.0 & 995 & 2481 & 61.7 & 59.2 \\
\hline & Total & 14,463 & 7,102 & 18.2 & 28.2 & 2,539 & 1,619 & 3.8 & 10.4 & 11,381 & 12,150 & 29.6 & 33.4 \\
\hline & $\mathrm{ASR}^{*}$ & & & 7.9 & 9.9 & & & & 2.1 & & & 9.8 & 11.3 \\
\hline \multirow{6}{*}{$\begin{array}{r}5 \text {-years } \\
\text { mortality }\end{array}$} & $<55$ & 3,424 & 656 & 9.4 & 11.6 & 478 & 339 & 8.4 & 5.0 & 1,336 & 1,145 & 14.7 & 12.0 \\
\hline & $55-74$ & 8,027 & 3,285 & 29.0 & 30.0 & 1,454 & 778 & 27.7 & 21.2 & 5,549 & 3,185 & 37.6 & 35.3 \\
\hline & $75-84$ & 2,563 & 2,346 & 63.2 & 60.9 & 531 & 385 & 52.7 & 45.2 & 3501 & 4739 & 68.2 & 61.1 \\
\hline & $85+$ & 449 & 815 & 85.5 & 81.6 & 76 & 117 & 84.2 & 74.4 & 995 & 2481 & 86.7 & 83.5 \\
\hline & Total & 14,463 & 7,102 & 32.2 & 44.5 & 2,539 & 1,619 & 31.0 & 27.4 & 11,381 & 12,150 & 48.6 & 53.0 \\
\hline & $\mathrm{ASR}^{*}$ & & & 13.7 & 15.9 & & & 13.2 & 7.2 & & & 17.1 & 15.7 \\
\hline
\end{tabular}

PAD: peripheral arterial disease of the lower extremities

*ASR: age-standardized rates (ASR) adjusted to European Standard

- Number of deaths $<3$

Table 3 28-day, 1-year and 5-year risk of death after hospital admission for acute myocardial infarction (AMI) compared to ischemic stroke or lower extremity arterial disease (PAD)

\begin{tabular}{|c|c|c|c|c|c|c|c|}
\hline & & \multicolumn{3}{|c|}{ AMI vs $P A D$} & \multicolumn{3}{|c|}{ AMI vs ischemic stroke } \\
\hline & & \multicolumn{3}{|c|}{ RR $(95 \% \mathrm{Cl})^{*}$} & \multicolumn{3}{|c|}{$\mathrm{RR}(95 \% \mathrm{Cl})^{* *}$} \\
\hline & & 28 days & 1 year & 5 years & 28 days & 1 year & 5 years \\
\hline \multirow[t]{5}{*}{ Men } & $<55$ & - & $2.20(1.24-3.91)$ & $1.13(0.82-1.54)$ & $0.60(0.43-0.83)$ & $0.62(0.50-0.77)$ & $0.64(0.54-0.76)$ \\
\hline & $55-74$ & $9.62(5.78-16.02)$ & $1.43(1.22-1.68)$ & $1.04(0.95-1.14)$ & $0.74(0.67-0.82)$ & $0.73(0.68-0.78)$ & $0.77(0.73-0.81)$ \\
\hline & $75-84$ & $4.99(3.39-7.36)$ & $2.00(1.67-2.41)$ & $1.20(1.10-1.31)$ & $0.90(0.84-0.97)$ & $0.89(0.83-0.94)$ & $0.93(0.89-0.96)$ \\
\hline & $85+$ & $2.10(1.21-3.65)$ & $1.19(0.93-1.53)$ & $1.02(0.91-1.13)$ & $0.81(0.73-0.90)$ & $0.91(0.83-1.00)$ & $0.99(0.94-1.03)$ \\
\hline & Total & $5.57(4.23-7.32)$ & $1.76(1.56-1.98)$ & $1.04(0.98-1.11)$ & $0.61(0.57-0.64)$ & $0.61(0.59-0.64)$ & $0.66(0.64-0.68)$ \\
\hline \multirow[t]{5}{*}{ Women } & $<55$ & - & $4.96(1.99-12.35)$ & $2.31(1.39-3.84)$ & $0.77(0.57-1.05)$ & $0.82(0.59-1.14)$ & $0.97(0.74-1.26)$ \\
\hline & $55-74$ & $14.28(6.68-30.52)$ & $2.84(2.14-3.76)$ & $1.42(1.23-1.64)$ & $0.75(0.66-0.84)$ & $0.75(0.68-0.82)$ & $0.72(0.67-0.76)$ \\
\hline & $75-84$ & $5.22(3.38-8.06)$ & $2.35(1.87-2.96)$ & $1.35(1.20-1.51)$ & $1.17(1.09-1.24)$ & $1.07(1.01-1.14)$ & $1.00(0.96-1.04)$ \\
\hline & $85+$ & $2.13(1.37-3.29)$ & $1.35(1.08-1.70)$ & $1.10(0.98-1.23)$ & $0.95(0.89-1.01)$ & $0.94(0.88-1.01)$ & $0.98(0.94-1.01)$ \\
\hline & Total & $6.64(4.99-8.84)$ & $2.75(2.37-3.20)$ & $1.62(1.49-1.77)$ & $0.83(0.80-0.88)$ & $0.80(0.77-0.84)$ & $0.80(0.77-0.82)$ \\
\hline
\end{tabular}

* Relative risk in patient with AMI compared to patient with PAD

${ }^{* *}$ Relative risk in patient with AMI compared to patient with Ischemic stroke 
Table 4 Gender differences in short-term and long-term mortality after first hospital admission in the Netherlands for acute myocardial infarction (AMI), peripheral arterial disease in the lower extremities (PAD) and ischemic stroke

\begin{tabular}{lccc}
\hline & $\begin{array}{r}\text { AMI } \\
\text { HR }(\mathbf{9 5 \% C l})^{*}\end{array}$ & $\begin{array}{r}\text { PAD } \\
\text { HR (95\%Cl)* }\end{array}$ & $\begin{array}{r}\text { Ischemic stroke } \\
\text { HR (95\%Cl)* }\end{array}$ \\
\hline $\begin{array}{l}\text { Crude } \\
28 \text { day }\end{array}$ & $0.60(0.56-0.64)$ & $0.67(0.47-0.96)$ & $0.88(0.83-0.92)$ \\
1 year & $0.62(0.58-0.65)$ & $0.90(0.81-1.20)$ & $0.87(0.83-0.91)$ \\
5 years & $0.66(0.63-0.69)$ & $1.15(1.03-1.29)$ & $0.88(0.85-0.92)$ \\
Adjusted & & & \\
28 days & $0.91(0.85-0.98)$ & $0.88(0.61-1.28)$ & $1.11(1.05-1.18)$ \\
1 year & $0.96(0.91-1.02)$ & $1.19(0.98-1.45)$ & $1.14(1.08-1.19)$ \\
5 years & $1.06(1.02-1.12)$ & $1.35(1.19-1.51)$ & $1.18(1.14-1.23)$ \\
\hline
\end{tabular}

* Hazard ratio in men compared to women

$\dagger$ Adjusted for age

\section{Discussion}

The present study shows that the dynamics of mortality over follow-up time clearly differ between patients first hospitalized for atherosclerotic diseases located at different vascular beds. Short-term mortality is the highest for ischemic stroke patients and the lowest for PAD patients. However, the risk of death increases considerably over follow-up time for PAD patients, and 5 years after first hospital admission the differences in risks of death between AMI- and PAD patients and between AMI- and ischemic stroke patients have largely disappeared.
Patients hospitalized for ischemic stroke have the highest risk of death compared to patients hospitalized for AMI or PAD. This finding was in agreement with the study of Caro et al. [8], were they reported crude five-year death rates of $33.2 \%$ and $41.8 \%$ for patients diagnosed with PAD and stroke respectively. Furthermore, they reported lower 5-year mortality risk for AMI patients $(26.6 \%)$ than for PAD patients. For women, this finding is in agreement. For men, however we observed similar risks of death between AMI and PAD patients.

The higher age of ischemic stroke patients may have affected risk of death but cannot fully explain the higher risk of death, as the age-standardized mortality rates were also higher for the ischemic stroke patients (Table 2).

The heart and the brains are vital organs, and disturbance of the functioning of these organs may be reflected in the high case-fatality among patients first hospitalized for AMI and ischemic stroke. It has been suggested that apart from the symptomatic atherosclerotic lesion, multiple stable or unstable lesions are present in the whole arterial vessel tree, predicting the patient's prognosis [15]. In addition, it has been suggested that atherosclerotic lesions occur predominantly in the large vessels first, with distal lesion occurring thereafter [16]. It is therefore likely that patients first hospitalized for PAD have atherosclerotic lesions in the whole arterial vessel tree. Our observation that PAD patients had more previous admissions for cardiovascular diseases than the AMI and ischemic stroke patients supports this

Table 5 Mortality among patients, who survive for at least 28 days after first hospital admission for acute myocardial infarction (AMI), peripheral arterial disease in the lower extremities (PAD), or ischemic stroke, by age and gender

\begin{tabular}{|c|c|c|c|c|c|c|c|c|c|c|c|c|c|}
\hline & \multirow{3}{*}{ Age } & \multicolumn{4}{|c|}{ Acute myocardial infarction } & \multicolumn{4}{|c|}{ PAD } & \multicolumn{4}{|c|}{ Ischemic stroke } \\
\hline & & \multirow[t]{2}{*}{$\begin{array}{r}\text { No. of } \\
\text { men }\end{array}$} & \multirow[t]{2}{*}{$\begin{array}{l}\text { No. of } \\
\text { women }\end{array}$} & Men & Women & \multirow[t]{2}{*}{$\begin{array}{l}\text { No. of } \\
\text { men }\end{array}$} & \multirow[t]{2}{*}{$\begin{array}{r}\text { No. of } \\
\text { women }\end{array}$} & \multirow{2}{*}{$\begin{array}{r}\text { Men } \\
\% \\
\text { deaths }\end{array}$} & \multirow{2}{*}{$\begin{array}{r}\text { Women } \\
\% \\
\text { deaths }\end{array}$} & \multirow[t]{2}{*}{$\begin{array}{c}\text { No. of } \\
\text { men }\end{array}$} & \multirow[t]{2}{*}{$\begin{array}{r}\text { No. of } \\
\text { women }\end{array}$} & \multirow{2}{*}{$\begin{array}{r}\text { Men } \\
\% \\
\text { deaths }\end{array}$} & \multirow{2}{*}{$\begin{array}{r}\text { Women } \\
\% \\
\text { deaths }\end{array}$} \\
\hline & & & & $\begin{array}{r}\% \\
\text { deaths }\end{array}$ & $\begin{array}{r}\% \\
\text { deaths }\end{array}$ & & & & & & & & \\
\hline \multirow{5}{*}{$\begin{array}{r}\text { 1-year } \\
\text { mortality }\end{array}$} & $<55$ & 3,284 & 618 & 1.5 & 1.7 & 224 & 335 & 5.3 & 0.9 & 1,245 & 1,059 & 2,3 & $\overline{1,5}$ \\
\hline & $55-74$ & 7,177 & 2,863 & 5.2 & 5,7 & 1,436 & 769 & 6.7 & 5.2 & 4,754 & 2,941 & 7,7 & 7,3 \\
\hline & $75-84$ & 1,888 & 1,646 & 15.0 & 13.2 & 503 & 363 & 14.1 & 11.6 & 2,478 & 3,526 & 18.4 & 14.6 \\
\hline & $85+$ & 275 & 489 & 28.7 & 26.0 & 62 & 95 & 35.5 & 27.4 & 519 & 1,432 & 26.6 & 29.3 \\
\hline & Total & 12,624 & 5,616 & 6.2 & 9,2 & 2,225 & 1,532 & 9.0 & 7.1 & 8,996 & 8,958 & 10.9 & 13.0 \\
\hline \multirow{5}{*}{$\begin{array}{r}\text { 5-year } \\
\text { mortality }\end{array}$} & $<55$ & 3,284 & 618 & 5.6 & 6.1 & 224 & 335 & 8.4 & 3.9 & 1,245 & 1,059 & 8,5 & 4,8 \\
\hline & $55-74$ & 7,177 & 2,863 & 20.5 & 19.7 & 1,436 & 769 & 26.8 & 20.2 & 4,754 & 2,941 & 27,1 & 26,8 \\
\hline & $75-84$ & 1,888 & 1,646 & 50.1 & 44.3 & 503 & 363 & 49.9 & 41.9 & 2,478 & 3,526 & 55.0 & 47.7 \\
\hline & $85+$ & 275 & 489 & 76.4 & 69.3 & 62 & 95 & 80.6 & 68.4 & 519 & 1,432 & 74.6 & 71.8 \\
\hline & Total & 12,624 & 5,616 & 22.3 & 29.7 & 2,225 & 1,532 & 22.9 & 24.7 & 8,996 & 8,958 & 19.5 & 39.6 \\
\hline
\end{tabular}

PAD: peripheral arterial disease of the lower extremities 


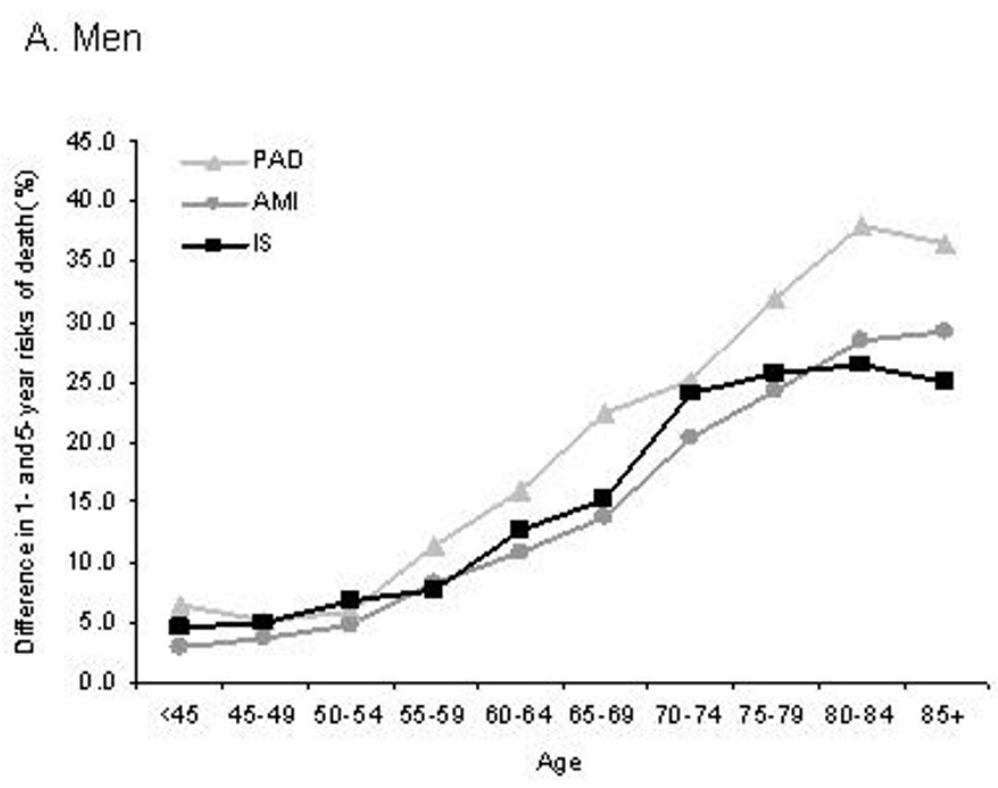

B. Women

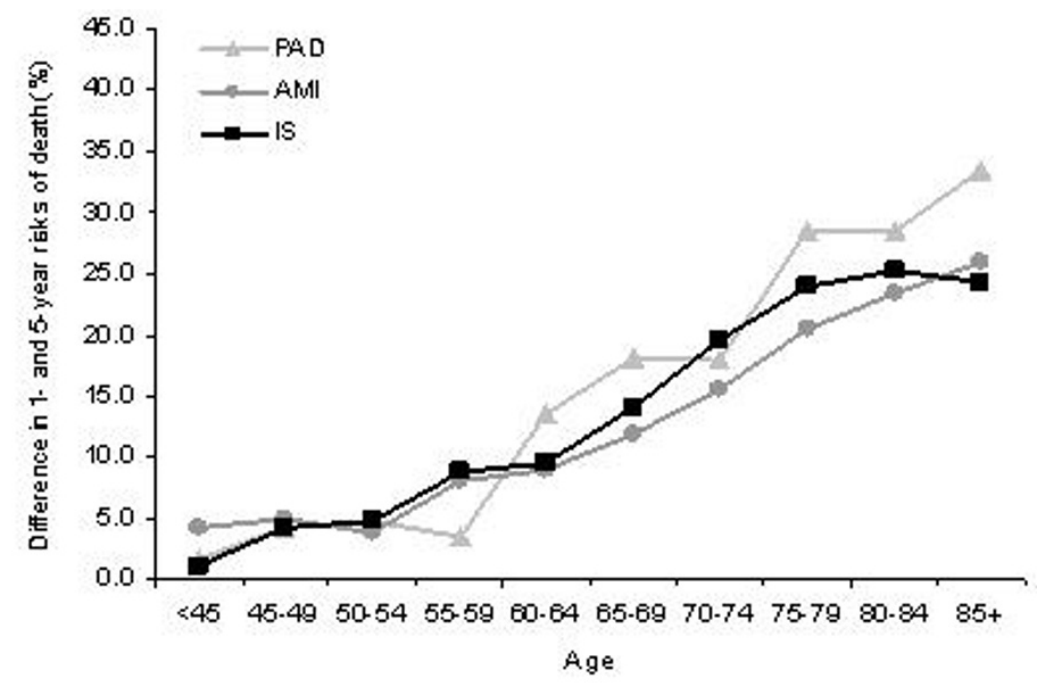

* 5-year risk of death minus 1 -year risk of death

Figure 2 The difference* between 1-year and 5-year risk of death (\%) after first hospital admission for acute myocardial infarction (AMI), peripheral arterial disease of the lower extremities (PAD) or ischemic stroke (IS), by age.

thought. The association of PAD with future cardiovascular disease events and CVD and total mortality has been demonstrated in multiple studies [17] and underlines the importance of secondary prevention among PAD patients, though PAD patients tend to be undertreated compared to patients with other manifestations of atherosclerosis, and it would appear that cardiovascular risk factor management for prevention in PAD patients is very modest $[18,19]$. Therefore, clinicians should be aware of the dynamics of mortality over follow-up time for patients admitted for different manifestations of atherosclerosis, in order to provide optimal secondary prevention treatment.

In this study higher age-adjusted 5-year risk of death after admission for AMI, PAD and ischemic stroke was observed for men. This is in agreement with findings from other studies for PAD and ischemic stroke patients $[20,21]$. Nevertheless, some factors that may be related 
to the patient's prognosis were differently distributed among men and women. Women were known to be older, have more diabetes and had a longer mean length of stay, while men were admitted to academic hospitals more often and had more previous admissions for ischemic stroke. Furthermore, other predictors for longterm risk of death may have been unequally distributed among men and women in the present study, thereby affecting the risk of death. For example, the prevalence of smoking, which is a risk factor for progression of atherosclerosis [8], is generally higher among men $[22,23]$. Smoking reduces survival in patients with atherosclerosis [24], and therefore smoking behavior might affect our results through over-estimation of the gender differences in mortality risk. Unfortunately, our study does not permit an in-depth evaluation of these estimates, since no information was available for most of the known predictors for prognosis following ischemic stroke, AMI and PAD.

\section{Strengths and limitations}

The strength of our study is the large size of the cohort, obtained from usual care, with a large age range and information on both men and women. Even though the validity of national registers has been questioned, several studies have shown that for the Netherlands the validity is adequate $[25,26]$ and a high validity of the linkage between the registers has been demonstrated $[26,27]$. Furthermore, for ICD- 9 codes 410,434 and 436 , the positive predictive values have been shown to be acceptable [28-30].

To appreciate the findings, the following needs consideration. The limitation of previous admissions to a maximum of 6 years may have resulted in some "firsttime" AMI, PAD or ischemic stroke patients (especially those older than 65 years) who were actually returning patients. The inclusion of returning patients may cause overestimation of absolute mortality rates (as returning patients are usually more severe patients), but not affect the difference between men and women, as there is no difference in return rate between men and women [31-33].

Mortality risks presented in this study are based on AMI patients hospitalized in 1995 and stroke and PAD patients hospitalized in $1997 / 2000$. However there is a substantial change in the way patients are treated now a day (especially AMI patients) and as a result of that current mortality risks may be lower.

Finally, the number of PAD patients was considerable smaller than the number of AMI and ischemic stroke patients. This is due to the fact that we decided to use ICD-9 code 443.9 for the identification of patients with peripheral arterial disease of the lower extremities (this code is described as peripheral vascular disease unspecified, intermittent claudication not otherwise specified). The PAD cohort would be much larger if we also used ICD-9 code 440.2 (atherosclerosis of the extremities), ICD-9 code 444.22 (arterial embolism or thrombosis of the lower extremities) and ICD-9 code 785.4 (gangrene). However, the PAD cohort would also become a case mix of patients with large differences in severity, symptoms and prognosis. Therefore only patients with ICD-9 code 443.9, representing moderate/ severe claudication patients (Fontaine stage IIb, III and IV respectively) were included in this study. The ICD-9 codes 440.2, 444.22 and 785.4 may represent the more severe forms of the disease compared to moderate/ severe claudication patients. Therefore, the risk of death after admission among these PAD patients is probably higher than observed risk of death presented in this study.

\section{Conclusions}

The present study shows that the dynamics of mortality over follow-up time clearly differ between patients first hospitalized for atherosclerotic diseases located at different vascular beds. Short-term mortality is the highest in ischemic stroke patients and the lowest for PAD patients. However, the risk of death increases considerably over follow-up time for PAD patients, and 5 years after first hospital admission the differences in risks of death between AMI- and PAD patients and between AMI- and ischemic stroke patients have largely disappeared.

Clinicians should be aware of the dynamics of mortality over follow-up time for patients admitted for different manifestations of atherosclerosis, in order to provide optimal secondary prevention treatment.

\section{Acknowledgements}

This study was supported by a grant from the Netherlands Heart Foundation (grant project 'Cardiovascular disease in the Netherlands: figures and facts').

\section{Author details}

'Julius Center for Health Sciences and Primary Care, University Medical Center Utrecht, Utrecht, the Netherlands. ${ }^{2}$ Netherlands Heart Foundation, The Hague, the Netherlands.

\section{Authors' contributions}

IV performed the statistical analysis and drafted the manuscript. ID participated in the design of this study and commented the draft. DG conceived of the study and commented the draft. MB conceived of the study, and participated in its design and coordination. All authors read and approved the final manuscript.

\section{Competing interests}

The authors declare that they have no competing interests.

Received: 16 December 2009 Accepted: 25 November 2010

Published: 25 November 2010

\section{References}

1. Kannel WB: Overview of atherosclerosis. Clin Ther 1998, 20(Suppl B):B2-17. 
2. Bray F, Guilloux A, Sankila R, Parkin DM: Practical implications of imposing a new world standard population. Cancer Causes Control 2002, 13:175-182.

3. Thorvaldsen P, Asplund K, Kuulasmaa K, Rajakangas AM, Schroll M: Stroke incidence, case fatality, and mortality in the WHO MONICA project. World Health Organization Monitoring Trends and Determinants in Cardiovascular Disease. Stroke 1995, 26:361-367.

4. Salonen R, Salonen JT: Progression of carotid atherosclerosis and its determinants: a population-based ultrasonography study. Atherosclerosis 1990, 81:33-40.

5. Witteman JC, Grobbee DE, Valkenburg HA, van Hemert AM, Stijnen T, Hofman A: Cigarette smoking and the development and progression of aortic atherosclerosis. A 9-year population-based follow-up study in women. Circulation 1993, 88:2156-2162.

6. van der KMeer, Smith RJA: Stroke patients in the general practice. [In Dutch]. Huisarts Wet 1990, 33:141-144

7. Vaartjes I, de Borst GJ, Reitsma JB, de Bruin A, Moll FL, Grobbee DE, Bots ML: Long-term survival after initial hospital admission for peripheral arterial disease in the lower extremities. BMC Cardiovasc Disord 2009, 9:43.

8. Caro J, Migliaccio-Walle K, Ishak KJ, Proskorovsky I: The morbidity and mortality following a diagnosis of peripheral arterial disease: long-term follow-up of a large database. BMC Cardiovasc Disord 2005, 5:14.

9. Koek HL, de Bruin A, Gast F, Gevers E, Kardaun JW, Reitsma JB, Grobbee DE, Bots ML: Short- and long-term prognosis after acute myocardial infarction in men versus women. Am J Cardiol 2006, 98:993-999.

10. Vaartjes I, Reitsma JB, de Bruin A, Berger-van Sijl M, Bos MJ, Breteler MM, Grobbee DE, Bots ML: Nationwide incidence of first stroke and TIA in the Netherlands. Eur J Neurol 2008, 15:1315-1323.

11. Hirsch AT, Haskal ZJ, Hertzer NR, Bakal CW, Creager MA, Halperin JL, Hiratzka LF, Murphy WR, Olin JW, Puschett JB, Rosenfield KA, Sacks D, Stanley JC, Taylor LM Jr, White CJ, White J, White RA, Antman EM, Smith SC $J$ r, Adams CD, Anderson JL, Faxon DP, Fuster V, Gibbons RJ, Hunt SA, Jacobs AK, Nishimura R, Omata JP, Page RL, Riegel B: ACC/AHA 2005 Practice Guidelines for the management of patients with peripheral arterial disease (lower extremity, renal, mesenteric, and abdominal aortic): a collaborative report from the American Association for Vascular Surgery/Society for Vascular Surgery, Society for Cardiovascular Angiography and Interventions, Society for Vascular Medicine and Biology, Society of Interventional Radiology, and the ACC/AHA Task Force on Practice Guidelines (Writing Committee to Develop Guidelines for the Management of Patients With Peripheral Arterial Disease): endorsed by the American Association of Cardiovascular and Pulmonary Rehabilitation; National Heart, Lung, and Blood Institute; Society for Vascular Nursing; TransAtlantic Inter-Society Consensus; and Vascular Disease Foundation. Circulation 2006, 113:e463-e654

12. Koek HL, de Bruin A, Gast F, Gevers E, Kardaun JW, Reitsma JB, Grobbee DE, Bots ML: Short- and long-term prognosis after acute myocardial infarction in men versus women. Am J Cardiol 2006, 98:993-999.

13. Bray F, Guilloux A, Sankila R, Parkin DM: Practical implications of imposing a new world standard population. Cancer Causes Control 2002, 13:175-182.

14. Reitsma JB, Kardaun JW, Gevers E, de Bruin A, van der Wal J, Bonsel GJ: [Possibilities for anonymous follow-up studies of patients in Dutch national medical registrations using the Municipal Population Register: a pilot study]. Ned Tijdschr Geneeskd 2003, 147:2286-2290.

15. Espinola-Klein C, Rupprecht HJ, Blankenberg S, Bickel C, Peth S, Kopp H, Victor A, Hafner G, Meyer J: [Manifestations of atherosclerosis in various vascular regions. Similarities and differences regarding epidemiology, etiology and prognosis]. Med Klin (Munich) 2002, 97:221-228.

16. Aboyans V, Lacroix P, Criqui MH: Large and small vessels atherosclerosis: similarities and differences. Prog Cardiovasc Dis 2007, 50:112-125.

17. Criqui $\mathrm{MH}$, Ninomiya JK, Wingard DL, Ji M, Fronek A: Progression of peripheral arterial disease predicts cardiovascular disease morbidity and mortality. J Am Coll Cardiol 2008, 52:1736-1742.

18. Cacoub PP, Bhatt DL, Steg PG, Topol EJ, Creager MA: Patients with peripheral arterial disease in the CHARISMA trial. Eur Heart J 2009, 30:192-201.

19. Watson $\mathrm{K}$, Watson $\mathrm{BD}$, Pater $\mathrm{KS}$ : Peripheral arterial disease: a review of disease awareness and management. Am J Geriatr Pharmacother 2006, 4:365-379

20. Hultgren R, Olofsson P, Wahlberg E: Gender differences in patients treated for critical limb ischemia. Eur J Vasc Endovasc Surg 2005, 29:295-300.
21. van Wijk I, Kappelle LJ, van Gijn J, Koudstaal PJ, Franke CL, Vermeulen M, Gorter JW, Algra A: Long-term survival and vascular event risk after transient ischaemic attack or minor ischaemic stroke: a cohort study. Lancet 2005, 365:2098-2104.

22. Bonarjee W, Rosengren A, Snapinn SM, James MK, Dickstein K: Sex-based short- and long-term survival in patients following complicated myocardial infarction. Eur Heart J 2006, 27:2177-2183.

23. Giskes K, Kunst AE, Benach J, Borrell C, Costa G, Dahl E, Dalstra JA, Federico $B$, Helmert $U$, Judge $K$, et al: Trends in smoking behaviour between 1985 and 2000 in nine European countries by education. J Epidemiol Community Health 2005, 59:395-401.

24. Braunstein JB, Cheng A, Fakhry C, Nass CM, Vigilance C, Blumenthal RS: ABCs of cardiovascular disease risk management. Cardiol Rev 2001, 9:96-105.

25. Mackenbach JP, van Duyne WM, Kelson MC: Certification and coding of two underlying causes of death in The Netherlands and other countries of the European Community. J Epidemiol Community Health 1987, 41:156-160.

26. Paas GRA, Veenhuizen KCW: Research on the validity of the LMR. [In Dutch]. Utrecht; 2002

27. De Bruin A, Kardaun JWPF, Gast A, de Bruin E, van Sijl M, Verweij G: Record linkage of hospital discharge register with population register: experiences at Statistics Netherlands. Statistical Journal of the United Nations Economic Commission for Europe 2004, 21:23-32.

28. Benesch C, Witter DM Jr, Wilder AL, Duncan PW, Samsa GP, Matchar DB: Inaccuracy of the International Classification of Diseases (ICD-9-CM) in identifying the diagnosis of ischemic cerebrovascular disease. Neurology 1997, 49:660-664

29. Ellekjaer $\mathrm{H}$, Holmen J, Kruger O, Terent A: Identification of incident stroke in Norway: hospital discharge data compared with a population-based stroke register. Stroke 1999, 30:56-60.

30. Merry AH, Boer JM, Schouten LJ, Feskens EJ, Verschuren WM, Gorgels AP, van den Brandt PA: Validity of coronary heart diseases and heart failure based on hospital discharge and mortality data in the Netherlands using the cardiovascular registry Maastricht cohort study. Eur J Epidemiol 2009, 24:237-247.

31. Bonarjee W, Rosengren A, Snapinn SM, James MK, Dickstein K: Sex-based short- and long-term survival in patients following complicated myocardial infarction. Eur Heart J 2006, 27:2177-2183.

32. Burn J, Dennis M, Bamford J, Sandercock P, Wade D, Warlow C: Long-term risk of recurrent stroke after a first-ever stroke. The Oxfordshire Community Stroke Project. Stroke 1994, 25:333-337.

33. Hata J, Tanizaki Y, Kiyohara Y, Kato I, Kubo M, Tanaka K, Okubo K, Nakamura H, Oishi Y, Ibayashi S, lida M: Ten year recurrence after first ever stroke in a Japanese community: the Hisayama study. J Neurol Neurosurg Psychiatry 2005, 76:368-372.

\section{Pre-publication history}

The pre-publication history for this paper can be accessed here: http://www.biomedcentral.com/1471-2261/10/57/prepub

doi:10.1186/1471-2261-10-57

Cite this article as: Vaartjes et al: The dynamics of mortality in follow-up time after an acute myocardial infarction, lower extremity arterial disease and ischemic stroke. BMC Cardiovascular Disorders 2010 10:57.

\section{Submit your next manuscript to BioMed Central and take full advantage of:}

- Convenient online submission

- Thorough peer review

- No space constraints or color figure charges

- Immediate publication on acceptance

- Inclusion in PubMed, CAS, Scopus and Google Scholar

- Research which is freely available for redistribution 